\title{
The multiplicity of self: neuropsychological evidence and its implications for the self as a construct in psychological research
}

\author{
Stanley B. Klein and Cynthia E. Gangi \\ University of California, Santa Barbara, California \\ Address for correspondence: Stan Klein, Department of Psychology, 551 Ucen Road, UCSB, Santa Barbara, CA 93106. \\ Klein@psych.ucsb.edu
}

\begin{abstract}
This paper examines the issue of what the self is by reviewing neuropsychological research, which converges on the idea that the self may be more complex and differentiated than previous treatments of the topic have suggested. Although some aspects of self-knowledge such as episodic recollection may be compromised in individuals, other aspects-for instance, semantic trait summaries - appear largely intact. Taken together, these findings support the idea that the self is not a single, unified entity. Rather, it is a set of interrelated, functionally independent systems. Implications for understanding the self in various areas of psychological research—e.g., neuroimaging, autism, amnesia, Alzheimer's disease, and mirror self-recognition—are discussed in brief.
\end{abstract}

Keywords: self; memory; neuropsychology

\section{What is the self?}

The phenomenology is compelling. Each of us has the experience of a unitary self, an "I" that remembers, chooses, thinks, plans, and feels. Yet it has been notoriously difficult to provide an account of just what this thinking, feeling, remembering, planning entity is. As Gordon Allport ${ }^{1}$ famously noted:

"Who is the I that knows the bodily me, who has an image of myself and a sense of identity over time, who knows that I have propriate strivings? I know all these things, and what is more, I know that I know them. But who is it who has this perspectival grasp?... It is much easier to feel the self than to define the self."

Bertrand Russell's ${ }^{2,3}$ distinction between knowledge by acquaintance and knowledge by description may be relevant to the difficulties that troubled Allport. According to Russell we have knowledge by acquaintance when we know something via direct personal contact (sensory or introspective) and manifest that knowledge by using terms referring to that knowledge to communicate with others. With respect to the self, this is seen in the ease with which we talk about the self as well as understand talk about self by others.
Problems quickly arise, however, when we try to pin down what it is we refer to by the word "self"when we are asked to describe what the word "self" means. Despite centuries of thought devoted to the problem, it has proven notoriously difficult to provide a set of propositions capable of transforming our acquired knowledge into a satisfying description of what a self is. ${ }^{4-15}$

The self, of course, is not alone in this regard. Similar issues arise, for example, with the word "time": "What, then, is time? If no one asks me, I know; if I wish to explain it to one that asked, I know not. .."16 This hardly is surprising, because the concepts of self and time are intimately related. ${ }^{17-19}$ Questions pertaining to the ontology of self, for example, include problems of synchronicity-i.e., what is it that accounts for the apparent phenomenal unity of self at a single moment - and diachronicity - i.e., the perceived continuity of self over time. Similarly, the notion of personal identity embodies the belief that the self, as presently experienced, is continuous with the self I experienced in the past and the self I will experience in the future. ${ }^{20}$ These, and a host of related, contentious, issues surrounding the word "self" make it clear that describing what we are talking about when we use the word "self" 
is a task for which insufficient progress has been made. ${ }^{21-24}$

When psychologists use the term "self," we thus often lack a clear conception of what the term is attempting to pick out-we have knowledge by acquaintance, but our knowledge by description is seldom up to the task. This is particularly problematic because the number of research papers devoted to self-related processes is proliferating at a staggering pace. For example, in the most recent issue of the journal Self and Identity (2009, Volume 8, jointly published as Issues 2 and 3) we identified from the table of contents the following potpourri of self topics: self-processes, self-control, self-verification, self-authorship, self-enhancement, self-esteem, selfregulation, self-improvement, self-protection, selfimage, self-threat, and self-stereotypes.

But what exactly is "the self" that serves as the object of this diverse set of predicates: What is being verified, authored, threatened, regulated? On the comparatively few occasions on which it has been attempted, ${ }^{25-27}$ psychologists have found it extraordinarily difficult to provide a convincing and coherent descriptive account of the self. Indeed, investigators often sidestep these difficulties, relying on their readers' familiarity with the term "self," derived from years of knowledge by acquaintance, to confer a sense of confidence that he or she knows to what it is the author refers.

\section{A different view of the problem of "the self"}

One difficulty in describing the "self" is that there may not be a single thing to be described. Rather, recent research suggests that the self is a multiplicity of related, yet separable, processes and contents. ${ }^{28,29}$ As Klein and colleagues ${ }^{30}$ have argued, instead of looking for a unitary entity we can describe as "the self," we should be breaking the problem into parts, studying aspects of the self separately before asking how they interact with one another to create the phenomenal appearance of unity.

\section{Contributions from neuropsychology}

Given the automatic and flawless way in which different cognitive systems normally interact, it is difficult to disentangle their respective contributions to knowledge about the self. However, because neuropsychological disorders can be quite selective-patients exhibit normal or near normal performance in some domains and profound impairments in others ${ }^{18,31}$ - they can provide a window into the operation of a component system in relative isolation, without the influence of other systems. By revealing differential patterns of impaired and preserved performance, the study of patients with neuropsychological impairments can illuminate aspects of a system's function and structure that are difficult to detect under normal operating conditions. $^{32,33}$

Applied to the self, recent neuropsychological studies suggest that the seemingly unitary self of everyday experience may be composed of several different, functionally isolable (though normally interacting) systems. ${ }^{28,29,34,35}$ These include, but are not limited to:

1. Episodic memories of one's life events. ${ }^{18,36-38}$

2. Semantic summary representations of one's personality traits. ${ }^{39-42}$

3. Semantic knowledge of facts about one's life. ${ }^{18,42,43}$

4. An experience of continuity through time: The "I" experienced now is connected to the "I" experienced at previous points (as well as later points) in one's life. Episodic memory is known to contribute heavily to this ability. ${ }^{44,45}$

5. A sense of personal agency and ownership: The belief-or experience-that "I" (agency) am the cause of "my own" (ownership) thoughts and actions. ${ }^{46,47}$

6. The ability to self-reflect: To form metarepresentations where the agent is the self, and make inferences on the basis of those representations. ${ }^{46,48,49}$

7. The physical self: The ability to represent and recognize (e.g., in mirrors, photographs) one's body. ${ }^{41,50,51}$

\section{The self and memory}

\section{Overview}

In the remainder of this paper, we focus on points 1,2, and 3 above-the roles of episodic and semantic memory in knowledge of one's self. First, we review evidence from case studies of patients suffering neurological disorders (e.g., amnesia, Alzhiemer's dementia, and autism) that demonstrate that episodic and semantic memory both contribute to our sense of self, although their relation is one of functional independence (i.e., 
although under normal circumstances they interact, one self-memory system can operate independently of the other ${ }^{32}$ ). We then draw on these results to help interpret findings from studies of self in the cognitive, clinical, and social literatures. Our goal is to discover which, if any, of our generalizations about the fractionation of self-memory systems might help us better understand the concept of self as it is used in psychological research.

Prior to presenting our Neurological casework, it is important to address the question of whether these participants, despite experiencing episodic amnesia, were able to access memory for lived events (albeit unconsciously), which could implicitly have influenced their semantic judgments. Because this concern was voiced by some of the reviewers it merits discussion.

We have two responses. First, in terms of definitions, episodic memory is held to be the conscious recollection of past personal events. ${ }^{34,52}$ Accordingly, the notion of unconscious episodic influence on semantic judgments is clearly at odds with the meaning of the term "episodic memory" as currently used in the literature.

However, one could reasonably adopt the position that exemplars, ${ }^{53}$ though not consciously available for verbal report, nonetheless are active at a subconscious level when a semantic decision is requested. Aware of this concern, my colleagues and $\mathrm{I}^{36,54}$ have devoted a substantial amount of our research (consisting in multiple methods-for example, priming techniques, transfer appropriate processing, the method of reversed association ${ }^{39,55}$ to show that exemplar-based self-knowledge is not activated (consciously or unconsciously) when participants perform semantic judgments about the self. $^{29,35}$

\section{Case studies neurological patients}

Approximately 15 years ago, Klein and Loftus ${ }^{36}$ proposed that the study of patients suffering amnesia might provide a particularly effective method for examining the respective contributions of episodic and semantic memory to self-knowledge. This is because amnesic patients often experience highly selective memory loss, typically displaying intact semantic memory with impaired access to episodic memory. ${ }^{32}$ Amnesic patients therefore present a unique opportunity to test alternative models of self-knowledge: tests of trait knowledge can be con- ducted in amnesic patients with assurance that episodic memory for traits is not involved.

If semantic memory contains a database of personality trait summaries (see point 2 ), then an amnesic patient should be able to know what he or she is like despite being unable to episodically recollect the particular experiences from which that knowledge was derived. There now is neuropsychological data from five patients: W.J., K.C., D.B., R.J., and K.R, that speak directly to this and other issues involving how types of knowledge about oneself are acquired and represented in memory.

W.J.: W.J. suffered a concussive blow to the head shortly after completing her first quarter in college. ${ }^{37}$ Interviews conducted shortly after her accident revealed that W.J. had forgotten much of what had happened during the preceding 12 months-a period of time that included her first quarter at college. To document her deficit in episodic memory, Klein and colleagues ${ }^{37}$ used the autobiographical memory cueing task originated by Galton ${ }^{56}$ and subsequently popularized by Crovitz and Schiffman. ${ }^{57}$ W.J. was asked to try to recall specific personal events related to cue words and to provide for each recollection as precise a date as possible. Initial testing revealed that she was unable to recollect personal events from the past year. Over the next month, however, her amnesia remitted, and when retested four weeks later, her performance had improved to the point that it was indistinguishable from that of neurologically healthy women who served as controls.

On two occasions-during her amnesia and after its resolution-W.J. was asked to provide personality ratings describing what she was like during her first quarter at college. While she was amnesic, W.J. was able to describe her personality; more importantly, the ratings she made during her amnesic period agreed with those she made afterward, as well as with independent raters who knew her at college. Thus, while W.J. was amnesic she knew what she had been like in college, despite the fact that she could not episodically recollect any personal events or experiences from that time period.

Could W.J.'s judgments while amnesic be based on her continued access to episodic recollections of high school or earlier-periods not covered by her amnesia? This seems unlikely. W.J., like many freshmen, manifested reliably different personality traits in college than she did in high school. This is not surprising given the new-found personal 
independence associated with the individual's abrupt change from his or her role(s) in family life to the freedom of college life. Yet W.J.'s selfratings during the amnesic period reflected her college personality to a reliably greater extent than they did her precollege personality. ${ }^{37}$ This suggests that W.J.'s ratings were based on semantic knowledge of her personality during her time at college, not on recollections of episodes long past.

K.C.: Although the case of W.J. supports the independence of semantic trait self-knowledge from episodic recollection, it might be argued that a partial overlap between her episodic knowledge of her precollege self may have enabled her to provide a reliable and accurate account of her trait selfknowledge during her amnesic episode. Such an account, however, fails to provide a viable explanation of the pattern of intact trait self-knowledge manifested by our next patient, K.C.

Patient K.C. permanently lost his entire fund of episodic memory following a motorcycle accident. ${ }^{42,45} \mathrm{He}$ also underwent a marked personality change following the accident. Nevertheless, K.C. was able to describe his postmorbid personality with considerable accuracy (his mother's ratings served as the criterion ${ }^{42}$ ). The fact that K.C. could accurately report his own personality traits supports the view that knowing oneself does not require retrieval of episodic memories. It is consistent with the hypothesis that personality information is stored independently from episodic memory, in the form of semantic trait summaries.

It is important to note that K.C.'s self-knowledge reflected his postmorbid personality, not his premorbid personality. This means that K.C. not only had access to semantic knowledge of his own personality traits, but he was also able to acquire new knowledge about his personality. Yet this updating occurred without his being able to episodically recollect any information about the behavioral events on which this updating presumably was based.

D.B.: The case of D.B. (like that of K.C.) shows that one can have accurate knowledge of one's own personality traits even with a total loss of episodic memory. Patient D.B. was a 79-year-old man who became profoundly amnesic as a result of anoxia following cardiac arrest. ${ }^{18}$ Both informal questioning and psychological testing revealed that D.B. was unable to recollect a single thing he had ever done or experienced from any period of his life. In addition to his dense retrograde episodic amnesia, he also suffered severe anterograde episodic memory impairment, rendering him incapable of recollecting events that transpired only minutes earlier.

To test D.B.'s semantic self-knowledge, we asked him on two occasions (separated by several weeks) to judge a list of personality traits for selfdescriptiveness. We also asked D.B.'s daughter (with whom he lives) to rate D.B. on the same traits. Our findings revealed that D.B.'s ratings were both reliable ( $r=0.69$ across sessions) and consistent with the way he is perceived by others $(r=0.64$ between D.B. and his daughter). (Age-matched controls showed $r s=0.74$ and 0.57 across sessions and raters, respectively). D.B. thus appears to have accurate and detailed knowledge about his personality despite the fact that he has no known conscious access to any specific actions or experiences on which that knowledge was based. ${ }^{34,42,58-60}$

Thus, like W.J. and K.C., D.B. manifests a clear dissociation between episodic and semantic selfknowledge. But can semantic knowledge of one's own personality traits dissociate from other types of semantic knowledge? Further testing of D.B. suggests that it can.

D.B.'s semantic memory also was affected by his illness, although this impairment was far less severe than that affecting his episodic memory. ${ }^{18}$ For example, although he knew a variety of general facts about his life, he showed a number of striking gaps in his life story. He knew the name of the high school he attended and where he was born, but could not recall the names of any friends from his childhood or the year of his birth. He also showed spotty knowledge of facts in the public domain. For example, although he was able to accurately recount a number of details about certain historical events (e.g., the Civil War), his knowledge of other historical facts was seriously compromised (e.g., he claimed that America was discovered by the British in 1812). Despite these impairments in D.B.'s semantic knowledge of his own personality was intact. This result suggests a dissociation within semantic memorybetween general semantic knowledge and semantic knowledge of one's personality traits.

Additional testing revealed a dissociation between D.B.'s knowledge of his own personality traits and the traits of others. For example, D.B. could not retrieve accurate knowledge of his daughter's personaity traits. The correlation between D.B.'s 
ratings of his daughter and her self-ratings was not reliable $(r=0.23)$, and was less than half that found between control parents' ratings of their child and the child's self-ratings $(r=0.61)$. Thus, although D.B.'s ability to retrieve accurate knowledge of his own personality was intact-i.e., it was no different from that of age-matched controls-he had lost the ability to retrieve accurate personality information about his adult daughter.

In short, D.B.'s case goes beyond the episodic/semantic distinction, suggesting categoryspecific dissociations within semantic memory. ${ }^{61}$ His ability to retrieve trait self-knowledge is intact; his ability to retrieve his daughter's traits is impaired; and his knowledge about the world at large (and specific facts about himself) is impaired. This pattern raises the possibility that the human cognitive architecture includes a subsystem of semantic memory that is functionally specialized for the storage and retrieval of trait self-knowledge. Additional data relevant to this claim comes from the case of K.R.

K.R.: K.R., a patient diagnosed with late-stage Alzheimer's dementia, shows that reliable, accurate knowledge of one's own personality can exist without the ability to update that knowledge. ${ }^{40,51}$

K.R.'s performance on standard tests of cognitive functioning (e.g., the Mini-Mental State Examination) indicated she suffers from late-stage dementia. She was disoriented for time and place and experienced difficulties with word finding and object naming. Her anterograde memory function was severely impaired, leaving her unable to recall events she had in mind only moments before. Knowledge of her personal past was sketchy. For example, she sometimes believed her late husband was alive, and her estimates of how long she has lived in her current facility ranged from 2 months to 14 years.

Despite these profound deficits, K.R. had reliable knowledge of her own personality traits. We asked her on two separate occasions to judge a list of personality traits for self-descriptiveness. We also asked K.R.'s daughter and her caregiver at the assisted living facility to rate K.R. on the same traits. The results showed that K.R.'s test-retest ratings were reliable $(r=0.86)$. However, her ratings did not agree with the ratings provided by either her daughter or her caregiver $(r s=0.31,-0.11$, for daughter and caregiver, respectively). This lack of consistency was not because the daughter and caregiver were poor judges of character; when asked to rate other individuals, their judgments correlated strongly with those of others.

How can K.R.'s ratings be so reliable, yet agree so little with those who know her best? According to her family, K.R.'s personality and behavior have changed dramatically as the disease progressed, but she seems unaware of her transformation (a situation fairly common among patients suffering Alzheimer's dementia) ${ }^{62,63}$ This suggests the possibility that the disease may have impaired K.R.'s ability to update the semantic records that store information about her personality. If her self-knowledge is intact but not being updated, then K.R.'s ratings may reflect her premorbid personality rather than her current one.

To test this hypothesis, we asked K.R.'s daughter to rate her mother on the same list of traits, only this time she was asked to base her ratings on her mother's personality prior to the onset of the disease. These ratings were strongly correlated with those provided by K.R. herself ( $r=0.59)$. So were preonset trait ratings of K.R. provided by her sonin-law $(r=0.79)$. Taken together, these findings indicate that K.R.'s ratings are accurate, but reflect her pre-Alzheimer's personality.

K.R. also knows her daughter's personality traits. When asked to rate her daughter on the same list of traits, her ratings correlated strongly with her daughter's self-ratings $(r=0.65)$. This is expected if K.R.'s fund of personality knowledge was created premorbidly, and remains intact. But if, as hypothesized, K.R. has lost the ability to update her semantic personality files, then her ratings should be inaccurate for people whom she first met after the onset of her dementia.

This was the case. On two occasions (weeks apart), K.R. was asked to rate her caregiver, whom she had been with for 2.5 years. K.R.'s test-retest reliability was low $(r=0.34)$, in striking contrast to the reliablity of her self-ratings $(r=0.86)$. Moreover, K.R.'s ratings of the caregiver did not overlap reliably with the caregiver's ratings of his own personality $(r=0.18)$. This is not due to the caregiver having a skewed view of himself. His self-ratings were strongly correlated with those provided by two age-matched, neurological healthy, women living in the same facility, who had known the caregiver for about the same length of time ( $r s=0.73,0.68)$. This also shows that K.R.'s inability to acquire new 
personality information is not a simple manifestation of the normal aging process. Clearly, the neurologically healthy age-matched controls were quite capable of acquiring accurate knowledge of the personality of someone they had recently met.

Thus, despite profound cognitive deficits, K.R. has intact knowledge of her own premorbid personality and that of her daughter. That her trait knowledge has been preserved and remains retrievable are remarkable given the difficulties she has retrieving ordinary facts from semantic memory: e.g., the names of everyday objects, what a clock looks like, where she is. Like the case of D.B., K.R.'s preserved self-knowledge suggests a dissociation within semantic memory, suggesting the presence of a functionally specialized database for the storage and retrieval of information about her personality.

It would appear, however, that the computational machinery responsible for updating personality knowledge (intact in K.C.) has been impaired in K.R. by the Alzheimer's disease. K.R. does not know her own current, postmorbid personality, nor has she been able to learn the personality traits of her primary caregiver.

R.J.: Patients K.C., W.J., and D.B. lost access to episodic memory as a result of brain trauma. However, there also are individuals for whom episodic memory fails to develop in the first place. ${ }^{64,65}$ Such developmental dissociations are particularly interesting because they permit inferences about the origins of self-knowledge that are not licensed by the discovery of dissociations caused by brain trauma and disease in adults.

Consider, for example, the hypothesis that semantic self-knowledge, despite being functionally independent of episodic memory, is initially constructed from a database of episodic memories. This hypothesis cannot be ruled out by cases like D.B., K.R., and W.J. Their intact semantic self-knowledge could have been derived from episodic memories acquired during the years prior to the brain trauma that caused their episodic loss as adults. But consider the implications of finding an individual who never has developed the ability to access episodic memories, yet has intact semantic self-knowledge. This developmental dissociation would suggest that building a semantic database of trait self-knowledge does not require access to a database of episodic memories.
Autism is a developmental disorder which has been hypothesized to impair the cognitive machinery that supports metarepresentations from developing normally. ${ }^{66,67}$ It has been proposed that episodic memories are stored in and retrieved via metarepresentations. ${ }^{68}$ If so, then autism should disrupt the normal development of episodic memory. To test this prediction, Klein, Chan, \& Loftus ${ }^{69}$ assessed the episodic memory of R.J., a 21-year-old male with diagnosed with autism.

Compared with ability matched controls, R.J. was found to be severely impaired on a variety of tests of recall, especially when memory for personally experienced events was tested (e.g., the Galton-Crovitz $\operatorname{task}^{56,57}$ ). Although his impairment was developmental in origin, his episodic performance was similar to that found in cases of amnesia caused by brain trauma. ${ }^{70}$

Despite his deficit in episodic retrieval, R.J. demonstrated reliable and accurate knowledge of his personality traits. His test-retest correlations were high ( $r=0.86$; I.Q. matched controls, $r=0.78)$. Moreover, the correlation between R.J.'s trait selfratings and his mother's ratings of him was significant $(r=0.56)$ and did not differ reliably from that obtained from control mother-son pairs $(r=0.50)$. R.J.'s self-ratings also were compared with ratings of R.J. obtained from one of his teachers; the correlation again was reliable $(r=0.49)$ and comparable to those obtained between control mother-son pairs.

These findings suggest that R.J.'s knowledge of what he is like accurately reflects how he is perceived by people with whom he interacts. ${ }^{71}$ But how did he acquire this trait self-knowledge? His case suggests that access to a database of episodic memories is not necessary. R.J. cannot retrieve episodic memories now and, because his impairment is developmental in origin, he probably never developed this ability in the first place. All four previously described cases-W.J., D.B., K.C., and R.J.- - show that trait self-knowledge can exist independently of episodic access; but R.J.'s developmental dissociation suggests that the acquisition of trait self-knowledge does not require episodic access (the same can be inferred for K.C.'s ability to update his knowledge of his personality).

As in the cases of K.R. and D.B., further tests of R.J. suggest content-specific dissociations within semantic memory. Klein and colleagues ${ }^{72}$ asked R.J. to judge features of common objects (e.g., Is a lemon 
sour? Is a balloon round?). R.J.'s answers were reliable across sessions $(r=0.77)$. However, they did not correlate with those provided by others of the same mental age. There was high agreement among I.Q. matched controls, with correlations among their answers ranging from 0.78 to 0.81 . In contrast, correlations between R.J.'s answers and theirs ranged from 0.18 to 0.33 .

R.J.'s atypical semantic knowledge is not due to a general inability to understand or answer questions-his ability to answer questions is fine, and when he is unsure what a term means, he requests clarification. This pattern-consensually accurate personality knowledge coexisting with odd, nonconsensual knowledge of foods, animals, and objects-is thus surprising. One would think the evidence of one's senses would allow the easy acquisition of knowledge about tastes, shapes, and colors. Indeed, words like sweet, tall, and large are more concrete and have more obvious referents than personality terms such as kind, friendly, and ungrateful. Nevertheless, an individual with autism was able to learn his own personality traits, but was unable to acquire consensually held knowledge of foods, animals, and objects.

It has been proposed that culturally shared knowledge results when domain-specific inference systems interact with linguistically transmitted information which the hearer stores-at least temporarily-in metarepresentations. ${ }^{73}$ Deciding which part of the message is relevant requires one to make inferences about the speaker's background beliefs and communicative intent-which also depends on metarepresentations. ${ }^{73}$ This proposal could explain why a person with autism-whose ability to form metarepresentations is likely limited-would have difficulty figuring out which knowledge is shared by those around him. Lacking normal metarepresentational abilities, R.J. would have difficulty inferring a speaker's beliefs and communicative intent. ${ }^{66}$ Without being able to store people's utterances in metarepresentations, apart from semantic memory, he would take everything said to him at face value. Other people's false beliefs, lies, ironic remarks, and metaphors would be stored in semantic memory as if they were true. Eventually this could have the effect of partially corrupting his database of world knowledge. ${ }^{67}$

More recently Klein and colleagues ${ }^{74}$ found that R.J. fails to accurately differentiate between the per- sonalities of his various family members, and that his ratings of them are less nuanced and less situationally specific than his ratings of his own personality. Specifically, despite the finding that R.J. has reliable and valid knowledge of his own personality traits, ${ }^{69}$ his ratings of other people (e.g., mother, father, brother) fail to accurately distinguish between their quite different personalities. Rather, he views them all as essentially the same (range of correlations $=0.75$ to 0.89 ) —in fact, R.J. gave his mother, father, and brother identical personality ratings on almost two-thirds of the traits he rated. This is not because his family members all share the same personality profiles. The correlations they provide for each other clearly indicate that they see themselves as reliably different (range: $r s=0.41-0.46$ ).

Moreover, it is not the case that R.J.'s ratings of his parents correlate highly because they present a uniform personality when interacting with himR.J. also sees his brother as very similar to his parents ( $r=0.87$ for his ratings of brother and father and $r=$ 0.75 for his ratings of brother and mother). Nor is R.J.'s failure to distinguish among family members a side effect of his mental age. T.M., a cognitively normal male of approximately the same mental age as R.J., distinguishes between his parents $(r=0.47)$, yet R.J. does not. Evidence presented in the case study also reveals that R.J.'s high correlations among family members was not due to a tendency to assign a socially desirable rating to everyone. ${ }^{74}$

Interestingly, R.J. was far more likely to assign extreme trait ratings_- "definitely" or "not at all" to family members than were appropriately matched control raters. Yet, his response repertoire is not restricted to the use of extreme categories. In rating his ratings of his own personality traits, R.J., often uses the intermediate category "somewhat." Indeed, in this respect his self-ratings did not differ reliably from self-ratings of cognitively normal controls. Moreover, R.J. used the category "somewhat" far more often in rating himself than in his ratings of others.

A "somewhat" generous (or kind or lazy) person may be someone who is moderately generous (or kind or lazy) in every situation. However, given that most human behavior shows considerable sensitivity to context, a more likely explanation is that "somewhat" reflects the perception that the individual being rated is (say) generous in some situations but not in others. On this view, R.J.'s use of 
"somewhat" indexes the extent to which he perceives an individual's behavior as varying across situations. If this line of inference is correct, then R.J. understands that his own behavior varies with the situation, but he fails to see the same is true (at least to the same degree) with respect to other persons.

This interpretation fits well with what is known about autism and theory of mind. As a result of this developmental disorder, it is hypothesized that the computational machinery that supports metarepresentation ${ }^{67}$ is impaired. As a consequence, people with autism have difficulty inferring other peoples' mental states, especially what others think, believe and know (i.e., the epistemic mental states). Our findings suggest that a person with autism can act on his own knowledge, whether he is meta-aware of that knowledge or not. As a result, R.J. can be aware of the ways in which his behavior varies as a function of context (at least as he construes it). However, his inability to correctly infer what other people believe, think, and know may be a barrier to his understanding how others construe their situations. To see the situational contingencies in the behaviors of his mother, father, and brother, R.J. would have to be able to infer what each of them thinks is happening in the situations in which they find themselves, even when what they think differs from what R.J. thinks. Yet many autistic individuals are notoriously poor at such "false belief" tasks. ${ }^{75}$

\section{Summing up}

The neuropsychological cases presented permit us to draw some tentative conclusions about how the cognitive architecture learns the personality traits of the individual in which it is situated.

1. Learning personality traits does not require access to episodic memories. K.C. learned about his postmorbid personality despite having no ability to retrieve episodic memories. R.J. also knows his personality traits, yet he cannot retrieve behavioral episodes from memory. Indeed, R.J.'s disorder is developmental in origin, suggesting that he has never been able to retrieve episodic memories.

2. Alzheimer's dementia can damage the mechanisms that allow one to learn about one's personality traits. Yet the inability to update personality self-knowledge need not interfere with the ability to retrieve information from an intact, preexisting semantic store of trait summaries (K.R.).

3. Any dissociation between semantic domainswhether due to brain trauma (W.J., K.C., and D.B.), neural disease (K.R.) or autism (R.J.) suggests functionally isolable storage and retrieval systems. But finding a developmental dissociation in R.J. suggests a functionally isolable acquisition system. His semantic dissociation suggests that trait self-knowledge is acquired via learning mechanisms that are functionally distinct from those that cause the acquisition of knowledge about animals, objects, foods, and people.

4. Five cases-W.J., K.C., D.B., K.R., and R.J.show that trait self-knowledge can exist independently of episodic access and may constitute a separate subsystem within semantic memory (e.g., R.J., K.R., and D.B.).

5. Trait self-knowledge is functionally independent of trait knowledge about other persons (D.B., R.J., M.J.H; for the case of M.J.H.).

\section{Implications}

Our research strategy is based on the idea that one way to determine what something is useful for is to look at situations in which it no longer is present. ${ }^{33}$ Guided by this principle, we examined neuropsychological case studies of cognitively impaired individuals to help map out the boundaries of a termthe self-that has been imprecisely delineated in much of psychological research.

While findings from individual case studies do not warrant broad conclusions about the nature of self-related function in the populations from which individual cases have been drawn, the general conclusions we have proposed about the self, per se, allow us to make some proposals and suggestions about its nature and function in a variety of domains and applications. In this section we draw out some of the implications of our findings about the multifaceted nature of self and apply them to research domains that rely (in varying degrees) on the concept of "self" to frame and/or interpret their findings.

\section{Autism}

Given the multifaceted nature of self, it should be clear that evidence of self-dysfunction in one 
aspect of autistic behavior should not automatically be construed as indicative of a general failure of self in autism. For example, the finding that autistic individuals fail to show a normal appreciation of the value of first person access to their internal states ${ }^{76}$ does not warrant a conclusion that selfunderstanding in general is deviant in autism (we are not suggesting that the authors have made this leap; rather we are warning readers to keep in mind that self-related findings in one context should not automatically be assumed reflective of the self generally). Nor does the finding that autistic individuals have been found to perform poorly on self-referent recall tasks. ${ }^{77}$ Such findings may suggest that autism entails deficits in organization and elaboration of episodic recollection, ${ }^{78}$ but it is unclear what they have to say about the cognitive structure of semantic trait self-knowledge, per $s e .^{78,79}$

Moreover, the absence of a normally functioning Theory of Mind in autism ${ }^{66}$ not necessarily license the assumption that knowledge of one's own mental states will suffer equally. For example, finding that people with autism show less empathy toward oth$\mathrm{ers}^{80}$ does not necessarily imply reduced empathic knowledge of self. ${ }^{69,81}$

What is warranted is that some aspects of selfknowledge may be impaired by an autistic disorder while others may be intact. The self, as we have argued, is not a thing that submits to all-or-nothing analysis. While aspects of autistic self-knowledge can show impairment, such findings do not warrant general conclusions about "the self in autism."

\section{Alzheimer's dementia}

Despite profound cognitive deficits, K.R. has intact knowledge of her own premorbid personality and that of her daughter. That her trait knowledge has been preserved and remains retrievable is remarkable given the difficulties she has retrieving ordinary facts from semantic memory-the names of everyday objects, what a clock looks like, where she is.

Like the other cases we have presented, K.R.'s preserved self-knowledge suggests a dissociation within semantic memory, consistent with the presence of a functionally specialized database for the storage and retrieval of information about personality. It would appear, however, that the computational machinery responsible for updating personality knowledge has been impaired in K.R. by her disease. K.R. does not know her own current, postmorbid personality, nor has she been able to learn the personality traits of her primary caregiver.

Neural dissociations in other patients suggest that personality knowledge is acquired via learning mechanisms that are specialized for that purpose (e.g., D.B.). Individuals with profound episodic amnesia can nevertheless update their trait self-knowledge (e.g., K.C.). Moreover, personality knowledge can be acquired despite developmental disorders that impair one's ability to acquire general world knowledge (as well as episodic retrieval; e.g., R.J.). By contrast, in K.R., we see a case where trait knowledge of self and other remains intact, but the ability to update that knowledge based on new experiences is no longer functional.

In a related study of Alzheimer's disease, ${ }^{51}$ we documented a similar pattern of memory performance for another aspect of self-one's physical appearance. In that study, patient P.H., an 83-year-old female in the late stages of the disease (she scores 7 on the Mini Mental State diagnostic procedure, where a score of 22 or less is considered "definitely abnormal" for members of her age group) was able to recognize herself from photographs taken during her early life (prior to age 40 years). By contrast, pictures of her taken from age 40 onward resulted in a far lower rate of recognition, with P.H. succeeding on only two of 20 opportunities.

These findings, taken together with those of K.R., suggest that aspects of self-knowledge (i.e., personality traits, facial appearance) that have been documented in clinical descriptions as degraded as a result of Alzheimer's disease, might degrade in such a way as to leave vestiges of earlier representational states. This idea is consistent with the proposal that Alzeimer's disease might carry with it impairment in procedures that update various semantic databases of self-related knowledge. ${ }^{40}$

These findings map well onto recent evidence that Alzheimer's dementia entails a gradual, temporally graded loss of generic world knowledge from semantic memory. ${ }^{82}$ Our results add to this literature by suggesting that this loss extends to aspects of semantic self-knowledge as well. ${ }^{83}$ In particular, we propose that a temporally graded breakdown in semantic memory function can account both for patient K.R.'s failure to update her semantic selfknowledge on the basis of personality changes taking place because the onset of her dementia. ${ }^{40}$ (It is, of course, a logical possibility that patient P.H.'s 
difficulties recognizing herself from pictures taken during the last several decades of her life may submit to a similar explanation). This conclusion has now received support from subsequent studies replicating these findings on larger samples of Alzheimer's patients. $^{84-86}$

Clinicians and families often characterize latestage Alzheimer's patients as lacking a sense of self. ${ }^{87,88}$ Our findings suggest a more nuanced view. Alzheimer's patients may be operating from knowledge of a former self, which may not be congruent with their current behavior. Clinicians and family may need to be sensitive to the possibility that such individuals may see themselves as they were, not as they are.

\section{Domain general learning}

Domain-general learning theories-connectionist or otherwise-presume that the same learning mechanisms account for knowledge acquisition across content domains. ${ }^{34}$ But a developmental dissociation (such as that shown by R.J.) that impairs the acquisition of knowledge about people, animals, objects, and foods, while having little effect on the acquisition of trait knowledge, is difficult to reconcile with such theories.

Such results are especially difficult for theories positing equipotential mechanisms that compute correlations between elementary perceptual or conceptual dimensions. Surely the evidence of one's senses is sufficient for R.J. and others to end up concurring that apples are sweet, lemons are not, rocks are hard, and giraffes are tall. Yet R.J. and others do not concur in their judgments of easily observable properties of food, animals, and objects. In contrast, R.J.'s judgments about his own personality are consistent with those of others who know him-even though R.J.'s judgments are those of an autistic individual with social deficits.

\section{Mirror self-recognition}

A considerable body of research has argued that a child's rudimentary awareness of self first emerges by approximately 18-24 months. The evidential basis for this conclusion is the finding that by this age most children are able to recognize themselves in a mirror. ${ }^{28,89}$

However, a recent study examining the ability of a patient suffering from Prosopagnosia (an impairment of face recognition following neurologi- cal damage) to draw accurate trait inferences from faces of persons he knows (including himself), but fails to recognize casts doubt on the usage of facerecognition as a means of establishing the first signs of self-knowledge in humans. ${ }^{41}$ Although the patient, M.J.H., is not reliably greater than chance when judging the faces of well-known others, his trait ratings achieved considerable accuracy when the face judged was his (despite the fact that he could not overtly recognize that face as belonging to him). ${ }^{41}$

This research suggests reliance on mirror selfawareness to establish the presence of self may be ill placed. While an ability to respond appropriately to one's image in a mirror may be a sufficient condition for identification of self-awareness, it clearly is not a necessary condition. As both the case of M.J.H. and K.H. ${ }^{51}$ have shown, an individual may possess accurate and detailed self-knowledge in the absence of an ability to identify self via visual channels. This is not surprising, given that the seemingly unitary self actually may be composed of a number of different, functionally isolable (though normally interacting) systems.

\section{Neuroimaging}

A considerable number of recent neuroimaging studies appear to be on a mission to locate the "self." But what is "the self" that neuroimagers attempt to capture with their pictures of the brain? The results, as the reviewers point out, thus far have been less than encouraging. ${ }^{90}$

As we have argued in this paper, the idea that there is a "self" to be found is based on the premise (in our estimation, false) that there is a "self to be found." Rather, as we have tried to show, the self consists in a collection of contents, aspects, and functions. No wonder meta-analytic assessments of the success of self-localization via imaging techniques have been discouraging. ${ }^{90}$ Different self-related tasks activate different aspects of the general construct, leading of necessity to a diversity of conclusions. Put more positively, what these studies seem to be saying is that the self is a multiplicity, and thus the idea of localizing an entity called the "self" is a nonstarter.

What ultimately is as important as the specificity with which our imaging techniques can capture mental/neural activity in the brain is the specificity with which our constructs can capture the essence of 
what they are intended to describe. ${ }^{91}$ As Polanyi, ${ }^{92}$ perhaps echoing Wittgenstein, long ago warned:

"... .either you know what you are looking for, and then there is no problem; or you do not know what you are looking for, and then you cannot expect to find anything." (p. 22).

\section{Episodic memory and identity through time}

As reported above, patient D.B. suffered a particularly dense amnesia affecting his memory for personal events, which occurred both before and after his illness. In contrast, his general knowledge and language skills appeared relatively intact. To document D.B.'s memory deficits, we administered a battery of tests designed to assess both anterograde and retrograde memory function. Testing revealed he had profound difficulty remembering events and experiences from his own past, but was able to provide accurate information about a number of issues and events that had been in the public domain. This pattern of selective memory impairment-a loss of the lived past accompanied by relative sparing of the known past-is consistent with a large body of research from experimental and cognitive neuroscience documenting dissociations between episodic and semantic memory functioning in amnesia. ${ }^{93}$

A novel contribution of the study of patient D.B. ${ }^{44}$ concerns the effects of his amnesia on his ability to imagine the future. In parallel with his difficulties remembering his personal past, D.B. had severe difficulty imagining what his experiences might be like in the future. ${ }^{45,94}$ By contrast, his capacity to anticipate issues and events in the public domain was largely indistinguishable from that of neurologically healthy, age-matched controls.

These findings may extend our understanding of the relation between memory and temporal identity. In an influential series of papers, Tulving ${ }^{42,45,95}$ argued that episodic memory differs from other forms of memory in that it alone enables one to relive personal events from the past and mentally project one's existence into the future. Tulving ${ }^{42,45}$ has coined the term autonoesis to describe the type of awareness accompanying episodic recollection that enables a person to mentally travel through subjective time. The impairment of personal temporal orientation suffered by patient like D.B. can thus be attributed to a disturbance in autonoetic consciousness.
While the research just reviewed might suggest the conclusion that absent episodic memory, a sense of self through time would be lacking or absent, this is not necessarily the case. Our research also suggests that semantic memory makes possible a form of mental time travel, albeit one that does not entail awareness of the temporal dimension of one's own experience. Specifically, D.B., who does possess semantic memory, is capable of knowing about, but not re-experiencing, previous states of the world and drawing on that generic knowledge to construct possible impersonal scenarios of the future. Thus, he may be able to infer his placement in a chronology of events without simultaneously being able to call up distinct, personal imagery of himself in that past and future.

It thus would seem that the ability to mentally travel back and forth in time is not wedded to a particular form of memorial experience; rather, there appear to be qualitatively different types of temporal experience associated with different forms of memory. It is the episodic variant, which appears primarily related to what might best be termed temporal personal identity. This is consistent with findings of identity loss accompanying episodic amnesia in dissociative identity disorders such as Fugue states. ${ }^{96}$

\section{Conclusions}

The case studies we have summarized add to a growing body of evidence demonstrating that some components of the self can be selectively spared while others are profoundly damaged. ${ }^{18,28,37,42,72,97}$ Across these cases, trait self-knowledge has been preserved in the face of impairments to episodic retrieval, ${ }^{18}$ personal temporality, ${ }^{44}$ general world knowledge ${ }^{40,72}$ and the meta-representational skills that allow self-reflection. ${ }^{40,49}$

In fact, to the best of our knowledge, there are no documented cases in which a person has lost trait self-knowledge while retaining other components of the self. Of the systems of self we have examined, the semantic self-knowledge system seems the most resilient in the face of the cognitive chaos resulting from developmental and/or environmental damage to the brain. This is both an empirical fact and a mystery for which we have, at present, no explanation. 


\section{Final thoughts}

At its most general level, our point is this. To understand what it means, cognitively, to have a "self," divide and conquer may be the best research strategy, and the fractionation provided by neuropsychological data may provide a particularly useful database. Although the corpus of relevant neuropsychological cases is still small, it already suggests that "the self" is actually composed of a number of functionally independent systems. ${ }^{28,29,34,90}$ These include, but are not limited to: (a) semantic representations of one's own personality traits, (b) episodic memories of one's own life, (c) knowledge of facts about one's own life, (d) a sense of personal agency and ownership, (e) the ability to self-reflect, (f) the experience of continuity of personal identity through time, and (g) ability to recognize representations of self (e.g., in mirrors, photographs).

By developing a careful model of each, one can eventually put the pieces together. Detailed, computationally explicit models of each piece will allow one to discover which components actually are the outputs of a single mechanism; when one component of the self requires another component to operate properly, without being reducible to that component; and when two (or more) components of the self coexist and jointly contribute to mental life, without requiring one another to operate. Paradoxically, a research strategy that assumes the self is divided may be the fastest way to learn how the parts come together to create the experience of unity derived from our knowledge of self by acquaintance.

\section{Conflicts of interest}

The authors declare no conflicts of interest.

\section{References}

1. Allport, G.W. 1961. Patterns and Growth in Personality. Holt, Rinehart \& Winston. New York, NY.

2. Russell, B. 1912/1999. The Problems of Philosophy. Dover Publications. Mineola, NY.

3. Russell, B. 1913/1992. Theory of Knowledge. Routledge. New York, NY.

4. Cassam, Q. 1997. Self and World. Oxford University Press. New York, NY.

5. Dainton, B. 2008. The Phenomenal Self. Oxford University Press. New York, NY.
6. Foster, J. 1991. The Immaterial Self. Routledge. New York, NY.

7. Gallagher, S. \& J. Shear. 1999. Models of the Self. Imprint Academic. Thorverton, UK.

8. Hasker, W. 1999. The Emergent Self. Cornell University Press. Ithaca, NY.

9. James, W. 1890. Principles of Psychology, Vol. 1. Henry Holt and Company. New York, NY.

10. Jopling, D.A. 2000. Self-knowledge and the Self. Routledge. New York, NY.

11. Kolak, D. 1999. Life, Death and Personal Identity: In Search of Myself. Wadsworth Publishing Co. Belmont, CA.

12. Kolak, D. \& R. Martin. 1991. Self \& Identity: Contemporary Philosophical Issues. Collier Macmillan Canada. Toronto, Canada.

13. Lapsley, D.K. \& F.C. Power. 1988. Self, Ego and Identity. Springer-Verlag. New York, NY.

14. Leary, M.R. \& J.P. Tangney. 2003. Handbook of Self and Identity. The Guilford Press. New York, NY.

15. Legrand, D. \& P. Ruby. 2009. What is self-specific? Theoretical investigation and critical review of neuroimaging results. Psychol. Rev. 116: 252-282.

16. Augustine, St. 1980. In Confessions. Gibb, J. \& W. Montegomery, Eds.: Garland Press. New York, NY. Translation by E. B. Pusey (1955).

17. Dalla Barba, G. 2002. Memory, Consciousness and Temporality. Kluwer Academic Publishers. Norwell, MA.

18. Klein, S.B., K. Rozendale \& L. Cosmides. 2002. A socialcognitive neuroscience analysis of the self. Soc. Cogn. 20: 105-135.

19. Klein, S.B., T.P. German, L. Cosmides \& R. Gabriel. 2004. A theory of autobiographical memory: necessary components and disorders resulting from their loss. Soc. Cogn. 22: 460-490.

20. Brennan, A. 1988. Conditions of Identity. Oxford University Press. New York, NY.

21. Baillie, J. 1993. Problems in Personal Identity. Paragon House. New York, NY.

22. Johnstone, H.W. 1970. The Problem of the Self. The Pennsylvania State University Press. University Park, PA.

23. Williams, B. 1973. Problems of the Self. Cambridge University Press. Cambridge, UK.

24. Sorabji, R. 2006. Self: Ancient and Modern Insights about Individuality, Life, and Death. The University of Chicago Press. Chicago, IL.

25. Conway, M.A. 2005. Memory and the self. J. Mem. Lang. 53: 594-628.

26. Neisser, U. 1988. Five kinds of self-knowledge. Philos. Psychol. 1: 35-39. 
27. Kihlstrom, J.F. \& S.B. Klein. 1994. The self as a knowledge system. In Handbook of Social Cognition. Vol 1. Basic Processes. Wyer, R.S. \& T.K. Srull, Eds.: 153-208. Erlbaum. Hillsdale, NJ.

28. Klein, S.B. 2001. A self to remember: a cognitive neuropsychological perspective on how self creates memory and memory creates self. In Individual Self, Relational Self, and Collective Self. Sedikides, C. \& M.B. Brewer, Eds.: 25-46. Psychology Press. Philadelphia, PA.

29. Klein, S.B. 2004. The cognitive neuroscience of knowing one's self. In The Cognitive Neurosciences III. Gazzaniga, M.A., Ed.: 1007-1089. MIT Press. Cambridge, MA.

30. Klein, S.B. in press. The self: as a construct in psychology and neuropsychological evidence for its multiplicity. WIREs: Cogn. Sci.

31. Parkin, A.J. \& N.R.C. Leng. 1993. Neuropsychology of the Amnesic Syndrome. Erlbaum. Hillsdale, NJ.

32. Tulving, E. 1983. Elements of Episodic Memory. Oxford University Press. New York, NY.

33. Weiskrantz, L. 1997. Consciousness Lost and Found. Oxford University Press. New York, NY.

34. Klein, S.B., L. Cosmides, J. Tooby \& S. Chance. 2002. Decisions and the evolution of memory: multiple systems, multiple functions. Psychol. Rev. 109: 306-329.

35. Klein, S.B., T.E. Robertson, C.E. Gangi \& J. Loftus. 2008. The functional independence of trait self-knowledge: commentary on Sakaki (2007). Memory 16: 556-565.

36. Klein, S.B. \& J. Loftus. 1993. The mental representation of trait and autobiographical knowledge about the self. In Advances in Social Cognition, Vol. 5. Srull, T.K. \& R.S. Wyer, Eds. Erlbaum. Hillsdale, NJ.

37. Klein, S.B., J. Loftus \& J.F. Kihlstrom. 1996. Selfknowledge of an amnesic patient: toward a neuropsychology of personality and social psychology. J. Exp. Psychol.: Gen. 125: 250-260.

38. Stuss, D.T. \& D.A. Guzman. 1988. Severe remote mmeory loss with minimal anterograde amnesia: a clincial note. Brain Cogn. 8: 21-30.

39. Klein, S.B., J. Loftus, J.G. Trafton \& R.W. Fuhrman. 1992. Use of exemplars and abstractions in trait judgments: a model of trait knowledge about the self and others. $J$. Pers. Soc. Psychol. 63: 739-753.

40. Klein, S.B., L. Cosmides \& K.A. Costabile. 2003. Preserved knowledge of self in a case of Alzheimer's Dementia. Soc. Cogn. 21: 157-165.

41. Klein, S.B., R.H. Gabriel, C.E. Gangi \& T.E. Robertson. 2008. Reflection on the self: a case study of a Prosopagnosic patient. Soc. Cogn. 26: 766-777.

42. Tulving, E. 1993. Self-knowledge of an amnesic individual is represented abstractly. In Advances in Social
Cognition, Vol. 5. Srull, T.K. \& R.S. Wyer, Eds.: 147-156. Erlbaum. Hillsdale, NJ.

43. Young, K. \& J.L. Saver. 2001. The neurology of narrative. Substance 30: 72-84.

44. Klein, S.B., J. Loftus \& J.F. Kihlstrom. 2002. Memory and temporal experience: the effects of episodic memory loss on an amnesic patient's ability to remember the past and imagine the future. Soc. Cogn. 20: 353-379.

45. Tulving, E. 1985. Memory and consciousness. Can. Psychol. 26: 1-12.

46. Frith, C.D. 1992. The Cognitive Neuropsychology of Schizophrenia. Erlbaum/Taylor \& Francis. East Sussex, England.

47. Gallagher, S. 2000. Philosophical conceptions of the self: implications for cognitive science. Trends Cogn. Sci. 4: 14-21.

48. Katzko, M.W. 2003. Unity versus multiplicity: a conceptual analysis of the term "self" and its use in personality theories. J. Pers. 71: 83-114.

49. Robinson, M.F. \& W. Freeman. 1954. Psychosurgery and the Self. Grune \& Stratton. New York, NY.

50. Gillihan, S.J. \& M.J. Farah. 2005. Is self special? A critical review of evidence from experimental psychology and cognitive neuroscience. Psychol. Bull. 131: 76-97.

51. Hehman, J., T.P. German \& S.B. Klein. 2005. Impaired self-recognition from recent photographs in a case of late-stage Alzheimer's disease. Soc. Cogn. 23: 116121.

52. Wheeler, M.A., D.T. Stuss \& E. Tulving. 1997. Toward a theory of episodic memory: the frontal lobes and autonoetic consciousness. Psychol. Bull. 121: 331-354.

53. Hintzman, D.L. 1986. "Schema abstraction" in a multitrace memory model. Psychol. Rev. 93: 411-428.

54. Klein, S.B., J. Loftus \& H.A. Burton. 1989. Two selfreference effects: the importance of distinguishing between self-descriptiveness judgments and autobiographical retrieval in self-referent encoding. J. Pers. Soc. Psychol. 56: 853-865.

55. Klein, S.B., S.H. Babey \& J.W. Sherman. 1997. The functional independence of trait and behavioral selfknowledge: methodological considerations and new empirical findings. Soc. Cogn. 15: 183-203.

56. Galton, F. 1879. Psychometric experiments. Brain 2: 149162.

57. Crovitz, H.F. \& H. Schiffman. 1974. Frequency of episodic memories as a function of their age. Bull. Psychon. Soc. 4(5B): 517-518.

58. Cermak, L.S. \& M. O'Connor. 1983. The anterograde and retrograde retrieval ability of a patient with amnesia due to encephalitis. Neuropsychologia 21: 213-234. 
59. Kircher, T.T.J., C. Senior, M.L. Phillips, et al. 2000. Towards a functional neuroanatomy of self processing: effects of faces and words. Cogn. Brain Res. 10: 133-144.

60. Starkstein, S.E., L. Sabe \& M.F. Dorrego. 1997. Severe retrograde amnesia after a mild closed head injury. $\mathrm{Neu}$ rocase 3: 105-109.

61. Caramazza, A. \& J. Shelton. 1998. Domain-specific knowledge systems in the brain: the animate-inanimate distinction. J. Cogn. Neurosci. 10: 1-34.

62. Mills, M.A. 1998. Narrative Identity and Dementia. Ashgate Publications, Ltd. Aldershot, UK.

63. Seigler, I.C., D.V. Dawson \& K.A. Welsh. 1994. Caregiver ratings of personality change in Alzheimer's Disease patients: a replication. Psychol. Aging 9: 464-466.

64. Ahern, C.A., F.B. Wood \& C.M. McBrien. 1998. Preserved vocabulary and reading acquisition in an amnesic child. In Brain and Values. Pribram, K., Ed.: 277-298. Erlbaum. Mahwah, NJ.

65. Vargha-Khadem, F., D.G. Gadian, K.E. Watkins, et al. 1997. Differential effects of early hippocampal pathology on episodic and semantic memory. Science 277: 376-380.

66. Baron-Cohen, S. 1995. Mindblindness: An Essay on Autism and Theory of Mind. MIT Press. Cambridge, MA.

67. Leslie, A.M. 1987. Pretense and representation: the origins of "Theory of mind". Psychol. Rev. 94: 412-426.

68. Cosmides, L. \& J. Tooby. 2000. Consider the source: the evolution of adaptations for decoupling and metarepresentation. In Metarepresentations: A Multidisciplinary Perspective. Sperber, D., Ed.: 53-115. Oxford University Press. New York, NY.

69. Klein, S.B., R.L. Chan \& J. Loftus. 1999. Independence of episodic and semantic self-knowledge: the case from autism. Soc. Cogn. 17: 413-436.

70. Boucher, J. \& D. Bowler. 2008. Memory and Autism. Cambridge University Press. Cambridge, UK.

71. Crane, L. \& L. Goddard. 2007. Episodic and semantic autobiographical memory in adults with autism spectrum disorders. J. Autism Dev. Disord. 38: 498-506.

72. Klein, S.B., L. Cosmides, K.A. Costabile \& L. Mei. 2002. Is there something special about the self? A neuropsychological case study. J. Res. Pers. 36: 490-506.

73. Sperber, D. \& D. Wilson. 1995. Relevance: Communication and Cognition, 2nd edn. Blackwell. Oxford, UK.

74. Klein, S.B., L. Cosmides, E.R. Murray \& J. Tooby. 2004. On the acquisition of knowledge about personality traits: does learning about the self engage different mechanisms than learning about others? Soc. Cogn. 22: 367-390.

75. Baron-Cohen, S., A.M. Leslie \& U. Frith. 1985. Does the autistic child have a "theory of mind"? Cognition 21: $37-46$.
76. Mitchell, P. \& K. O’Keefe. 2008. Brief report: do individuals with autism spectrum disorder think they know their own minds? J. Autism Dev. Disord. 38: 15911597.

77. Toichi, M. 2008. Episodic memory, semantic memory and self-awareness in high-functioning autism. In Memory and Autism. Boucher, J. \& D. Bowler, Eds.: 143-165. Cambridge University Press. Cambridge, UK.

78. Klein, S.B. \& J. Loftus. 1988. The nature of self-referent encoding: the contributions of elaborative and organizational processes. J. Pers. Soc. Psychol. 55: 5-11.

79. Klein, S.B. \& J.F. Kihlstrom. 1986. Elaboration, organization, and the self-reference effect in memory. J. Exp. Psychol: General 115: 26-38.

80. Hobson, J.A., R. Harris, R. Garcia-Perez \& R.P. Hobson. 2009. Anticipatory concern: a study in autism. Dev. Sci. 12: 249-263.

81. Lombardo, M.V., J.L. Barnes, S.J. Wheelwright \& S. Baron-Cohen. 2007. Self-referential cognition and empathy in autism. PloS ONE 9: 1-11.

82. Westmacott, R., M. Freedman, S.E. Black, et al. 2004. Temporally graded semantic memory loss in Alzheimer's disease: cross-sectional and lognitudinal studies. Cogn. Neuropsychol. 21: 353-378.

83. Kazui, H., M. Hashimoto, N. Hirono \& E. Mori. 2003. Nature of personal semantic memory: evidence from Alzheimer's disease. Neuropsychologia 41: 981-988.

84. Harrison, B.E., B.A. Therrien \& B.J. Giordani. 2005. Alzheimer's disease behaviors from past self-identities: an exploration of the memory and cognitive features. Am. J. Alzheimer's Dis. Other Dement. 20: 248254.

85. Rankin, K.P., E. Baldwin, C. Pace-Savitsky, et al. 2005. Self awareness and personality change in dementia. $J$. Neurol. Neurosurg. Psychiatry 76: 632-639.

86. Ruby, P., F. Collette, A. D’Argembeau, et al. in press. Perspective taking to assess Self-personality: what's modified in Alzheimer's disease? Neurobiol. Aging.

87. Cohen, D. \& C. Eisdorfer. 1986. The Loss of Self: A Family Resource for the Care of Alzheimer's Disease and Related Disorders. W.W. Norton. New York, NY.

88. Ronch, J.L. 1996. Mourning and grief in late life Alzheimer's dementia: revisiting the vanishing self. Am. J. Alzheimer's Dis. 11: 25-28.

89. Parker, S.T., R.W. Mitchell \& M.L. Boccia. 1994. SelfAwareness in Animals and Humans: Developmental Perspectives. Cambridge University Press. New York, NY.

90. Ruby, P. \& D. Legrand. 2007. Neuroimaging the self? In Sensorimotor Foundations of Higher Cognition. Rossetti, Y., P. Haggard \& M. Kawato, Eds.: 22nd Attention \& 
Performance Meeting, pp. 293-318. Oxford University Press. New York, NY.

91. Uttal, W.R. 2001. The New Phrenology. MIT Press. Cambridge, MA.

92. Polanyi, M. 1967. The Tacit Dimension. Anchor Books. Garden City, NY.

93. Schacter, D.L. \& E. Tulving, Eds. 1994. Memory Systems 1994. MIT Press. Cambridge, MA.

94. Dalla Barba, G., J.Y. Cappelletti, M. Signorini \& G. Denes. 1997. Confabulation: remembering another' past, planning another's future. Neurocase 3: 425-436.
95. Tulving, E. \& M. Lepage. 2000. Where in the brain is the awareness of one's past. In Memory, Brain, and Belief. Schacter, D.L. \& E. Scarry, Eds.: 208-228. Harvard University Press. Cambridge, MA.

96. Kihlstrom, J.F. \& D.L. Schacter. 1995. Functional disorders of autobiographical memory. In Handbook of Memory Disorders. Baddeley, A.D., B.A. Wilson \& F.N. Watts, Eds.: 337-364. Wiley. New York, NY.

97. Rathbone, C.J., C.J.A. Moulin \& M.A. Conway. 2009. Autobiographical memory and amnesia: using conceptual knowledge to ground the self. Neurocase 15: 405-418. 